\title{
Study on the Teaching Mode of College English Writing from Meme Perspective
}

\author{
Tian li \\ Foreign language School, Hubei University of Traditional Chinese Medicine \\ Wuhan, China \\ 443117353@qq.com
}

\begin{abstract}
In college English teaching, how to effectively improve the writing skill of the students has always been a great concern to the teacher. This article aims to work out an effective and feasible teaching mode from the perspective of meme to improve the writing ability of college students. The author conducts a detailed study on the characteristics of the imitation and variation of memes in the process of cultural communication and the relationship between language memes and the teaching of English writing. It can be found that language memes greatly help students acquire an effective way to improve their language proficiency and practice innovative writing based on imitation. Therefore, in this paper, the suggestion of taking full advantage of the function and uniqueness of the language memes in the teaching of college English writing is put forward, and some concrete methods of the application of memes in teaching of college English Writing are also proposed.
\end{abstract}

Keywords-Meme; College English teaching; Teaching mode; Imitation

\section{INTRODUCTION}

In recent years, the upsurge of English teaching reform has caused many English teachers to put forward their own views on how to adapt to the new teaching reform and speed up the adjustment of English teaching methods and contents. Many researchers have focused their attention on linguistic theories, hoping to find some inspiration for adjusting English teaching. Memetics, as one of the most influential linguistic theories, has attracted much attention. It can not only help people understand the process of human thinking, but also give people some enlightenment on how to carry out teaching activities through taking full consideration of characteristics displayed in the process of students' learning of English. College English teaching has always been the focus and difficulty in college education.

Although colleges and universities have invested a lot of human and material resources to ensure the efficiency of English teaching and improve students' English ability, the results are not significant. English ability of many college students, especially their writing ability, still needs improving. In order to help college English teachers enhance their efficiency in teaching students how to write properly, the paper aims at offering some suggestions from the perspective of meme based on Memetics.

\section{INTRODUCTION TO MEMETICS}

Memetics, as an important linguistic theory, reveals how culture develops and influences people's thinking in the process of communication. The core term of this theory, memes, refers to "the most fundamental unit in the dissemination of cultural information" [1]. The theory of Memetics is first put forward by Richard Dawkins, a famous scholar, in the book selfish gene which is based on Darwin's theory of evolution and further applies Darwin's theory to the study of cultural development. As far as the behavior of communication is concerned, here meme refers to "cultural gene", that is, people imitate and inherit a certain cultural phenomenon, and internalize this cultural phenomenon into a part of their brain thinking, thereby affecting other ways of thinking and activities. This theory is very suitable for the analysis of complex linguistic phenomena, so researchers have applied this theory to many research fields.

\section{A. The Focus of Memetics}

Memetics mainly focuses on studying the role memes play in various social and linguistic phenomena and in the promotion of their development and on the classification of memes. The fundamental of Memetics is based on the meaning of imitation. The etymological origin of memes comes from the Greek word "mimeme", which means "imitation", and the definition of memes in the Oxford English Dictionary is the basic unit of culture, transmitted by non-genetic means, especially by imitation [2]. It can be seen that the basic feature of meme replication is imitation, and imitation is the key to the transmission of memes. It is imitation that determines that meme is a replication factor and gives it the ability to replicate. French sociologist Gabriel Tarde, in his 1890 book The Law of Imitation, pointed out that all the similarities in the origin of social communication are the direct or indirect results of various forms of imitation.

The whole history of human beings is a history of imitation, in which the inspiration of an individual's invention is shared by all. Wealth. Imitation is the basic principle of social development and existence, and is the root of social progress. It seems that all social behaviors of human beings are learned through imitation. All individuals in society are imitating each other's social behavior. The reappearance of the "law of world repetition" in human society mainly depends on imitation. Human society is to imitate, learn and create from each other. 


\section{B. The Importance of Memetics}

As Memetics has always played such an important role in study on culture and language, its application mainly includes the following aspects: Firstly, many scholars have applied this theory to the study of linguistic phenomena. Cai Shaolin has based the analysis of linguistic variation on Memetics. A series of changes will take place in the process of language use and communication. Although the main content of language has not changed much, a series of changes will take place in the form of language use. "These changes can promote the further development of language and exert profound effects on the development of culture" [4]. In addition, some researchers have applied Memetics in the field of applied teaching. Han Zhengzheng has explored how to apply Memetics to the teaching of English vocabulary. In the past, English teacher, to a large extent, rely solely on repetition to help students master English vocabulary, but the ultimate outcome has not been satisfactory. "In order to solve this problem, English teachers must help students establish the relevance between words, so that students can effectively improve the efficiency in memorizing and mastering English words" [5]. Additionally, some researchers, such as He Ziran and He Xuelin, apply Memetics to the study on the analysis of meme transmission in sociopragmatic phenomena. These studies fully demonstrate the necessity of applying Memetics to the research on language teaching, which is also the major concern of this study.

\section{Memetics And TeAching of College English WRITING}

Memetics makes us realize that the process of language communication is the process of replication and transmission of language memes. The reason why language can be used as a universal tool of communication and has survived during human evolution of civilization over thousands of years is that, as a meme it is constantly used and imitated by its users. If a language is no longer imitated and used by people, it must gradually be reduced into oblivion and disappear into people's lives.

According to the classification of memes mentioned above, language memes can also be divided into "genotypes one and phenotypes ones" [6]. Fully understanding the characteristics of these two genres of language genes, teachers can help the students improve their writing ability in the teaching. Memetics explores the process of transmission and development of memes, which is also one of the characteristics of language learning. Therefore, the combination of Memetics and research of language teaching has become an inevitable trend.

\section{A. The Classification of Memes and Its Characteristics}

Memes are characterized by the property of reservation, variability and selectivity. Every meme is both the replication and inheritance of previous meme, in which a certain variation is generated in the process of replication and transmission. Every meme sustains its development in constant variation. Here imitation and replication do not mean the exact and one hundred percent clone of the meme. It's actually a reorganization of memes. For this reason, it can be believed that innovation originates from memes. So does the learning of language as the seeds of invention comes out of imitation. Imitation can speed up the transition from the understanding to the application of language. It is inevitable to achieve the originality in language from the initial learning and imitation. Countless practice has fully proved that any creative use of language starts with the simple and mere imitation. Without imitation and inheritance in the learning of language, there is no any possibility in the creation and innovation in language. The process of language is the process of imitating and spreading language memes. Memetics of language tells us that the premise of copying memes is that there must be memes for the language learners to imitate. Imitating writing is a quite traditional way of writing based on the combination of reading and writing. Through imitation, students can acquire a simple and convenient way of writing and the time for students to explore direct experience can be greatly shortened. New inspirations can be easily drawn from others' success and new cognition can be achieved, which can accelerate the transition from the understanding of language to its application. A new study on the teaching of imitating writing from the perspective of Memetics can help emphasize the importance of imitation, which enable the students to obtain an effective way of enriching language and practice innovative writing based on imitation.

Memes can be roughly divided into two categories: genotypic memes and phenotypic memes [6]. The difference lies in that the former refers to the memes in the process of transmission. Though the original memes and replicative memes are consistent in their content, but differ in their forms. The diversified forms of replicative memes ensure the enrichment and diversification of memes in the process of communication which profoundly promote the development and expansion of memes. The latter, phenotypic meme, refers to in the process of transmission, the imitative and the original meme can be consistent in form, but some changes are presented in the content. These two categories of memes can help people to further understand the causes and characteristics of specific phenomena of cultural communication.

Genotypic language memes indicate that the replication and dissemination of content of information is achieved through various ways and forms. Information embedded in those language memes, the core of imitation and dissemination, remains the same but in different forms. Genotypic language memes are actually memes same in content but different in shapes or forms, whose transmission features direct imitation or the replacement of substitutes similar in content but different in forms.

As far as the teaching of College English writing is concerned, direct imitation can be achieved through the quotation of important words, phrase or sentences into the writing of essays. In the new versions of College English texts and exercises attached behind, idioms, proverbs, colloquial expressions, famous quotes and famous verses and verses are not difficult to be found. Concise in diction, condensed in meaning but profound in philosophical connotation, they not only reflect the accumulation of language and culture but also wisdom of human civilization. Those classical and valuable materials of language can just serve as language memes of direct imitation for the students when they practice their essay 
writing. Direct application of language memes should be greatly advocated when teachers teach the students how to improve their writing skills. Epigrams, such as, "Genius is one percent inspiration and ninety-nine percent perspiration", are often used at the beginning or the end of a composition, which not only makes the composition full of vitality and philosophical profundity, but also highlights the theme and echoes the author's views.

Phenotypic language memes, though, similar in forms, differ from each other in the information or message embedded in them when they are imitated and disseminated. They are characterized by the transmission of different information in the same form. Phenotypic memes imitate well-established linguistic structures and then change the original linguistic information or its components to express different meanings according to different contexts. The enlightenment teachers obtain from phenotypic language memes in the teaching of College English writing is to teach students to bestow different meanings in the same language form according to different contexts, forming new meme complex.

Homomorphic association can be used as a good mode to illustrate the working mechanism of phenotypic language memes. Phenotypic language memes appear in different contexts in the same form can make people associate them with different matters. Changes take place in the process of reproduction and transmission of language memes, among which variation in meaning is an important way of language meme change. Chinese scholars Xie Zhaoqun and He Ziran think that the variation of meme is essentially the change of meaning. Though no trace of any slight change in the form of certain memes can be found, the meanings contained in those meme can are likely to vary with different expressive needs of language users.[7] Besides direct, literal and conceptual meanings indicated in dictionaries, language uses can still find colorful connotations or associative meanings in those language memes. Isomorphism refers to the reproduction of a memetic phenotype with new meaning by imitating a known linguistic structure in the process of transmission. These linguistic phenomena are similar in form but different in content. The language structure that first acts as a meme parent can be a classical sentence, a paragraph or a discourse. They are easy to be imitated and are highly derivable memes. From the perspective of language use, these memetic phenomena transform language and promote innovation on the basis of familiarity.

\section{B. Problems in Current Teaching of College English Writing}

As an important part of English learning, English writing has always been concerned by teachers and students. However, at present, the writing ability of college students still needs to be improved. There are still many problems in the teaching of College English writing, mainly in the following aspects.

First, at present, the biggest problem facing college students in English learning is the expansion of English vocabulary. An important reason why many students can not improve their English writing is that their vocabulary cannot meet the standards of curriculum. The reasons for this problem can be summed up in two aspects: firstly, the requirements prescribed in the English curriculum for students to master the vocabulary are far higher than those of the English curriculum for senior middle school students. Most non-English majors have not increased significantly their English vocabulary since they entered the university, and even for some students' their English vocabulary has decreased gradually. Secondly, many students recite English words improperly, resulting in a poor efficiency in the memory of English vocabulary. What's more, their interest in English learning will also be reduced accordingly.

Second, the mastery of grammatical knowledge will also have a far-reaching effect on the improvement of students' writing ability. At present, many college students are still weak in their knowledge of grammar. In order to attain good results in important examinations, students will naturally concentrate all their energy and time on the regular contents of the examinations. As multiple choices constitute larger part of the English test paper, especially in senior high school, they cannot completely test the students' real English level, and even many students will try to figure out the teachers' psychology to find a shortcut in answering the test paper. Obviously, answering questions correctly does not guarantee that students really have mastered these words and grammatical points. It is quite common that the improper use of words and grammatical mistakes contribute to the poor performance in English writing.

Third, in China, many non-English majors are not quite familiar with the cultures of those English-speaking countries, especially the cultural knowledge related to specific words and phrases. Although many college students can make full use of the Internet resources to collect relevant information, and even many students watch English movies in their spare time, but the cultural knowledge presented in these movies still has a very limited positive impact on their writing. The lack of understanding of the culture of the English-speaking countries will bring some problems to their English writing. Many students will feel that it is hard to express their ideas or feelings in the actual writing, which is undoubtedly related to their lack of cultural knowledge and vocabulary.

\section{The Application of Memes in the Teaching of College English Writing}

In view of the problems with the teaching of English writing, teachers should start with improving students' vocabulary and grammatical knowledge, and gradually enhance students' English writing ability. The application of Memetics can not only help teachers achieve high efficiency in teaching students how to write, but also help promote students' confidence and ability of English writing.

First, students should be encouraged to imitate the excellent model essays to enlarge their vocabulary. The application of Memetics in College English writing is mainly reflected in fully exerting the power of excellent English model essays and helping students gradually improve their English writing ability. In excellent model texts, in addition to the normative and reasonable structure, the language used in them is also appropriate and graceful. There are some more commonly used words, that is, the language memes, which can greatly help improve the quality of the articles. For example, the use of 
some conjunctions or phrases, such as in the first place, in summary and so on, will greatly strengthen the logic of the article and add a lot of flavors to the article. Such an introduction and imitation of these model essays of high quality will certainly help students form good English writing habits.

Second, excellent model essays can also help students further understand the culture of western countries. Compared with Chinese articles, English users tend to pay more attention to the logicality and structure of the article. English essays, especially argumentative essays, often have a specific format. Generally speaking, for non-English majors, they need to maintain the consistency through the beginning to the end of the article, that is, the beginning of the article must present the theme and the central idea, and finally the end should echo the beginning, summarizing the main idea of the article once again. The main body of the article should demonstrate and support the theme in a logical arrangement. Many excellent English essays, especially those introducing the customs and customs of Western countries, can help students to increase their understanding of Western culture.

Third, teachers can also help students deepen their understanding of grammar by analyzing some syntactic structures in the model texts. It is often more intuitive to explain the usage of a certain kind of clause through typical examples, and students can understand the clause more profoundly. However, it is an arduous task to demonstrate grammatical knowledge through model texts. Teachers must persevere in doing so in order to help students improve their English writing ability significantly.

\section{STRATEGIES FOR THE TEACHING OF ENGLISH WRITING BASED ON MEMETICS}

College English teachers should make full use of the role of meme transmission, that is, they should make full use of excellent model essays to promote students' ability of English writing. As we know, the excellent model essays can be considered as a treasures of language memes concerning the usage of words and phrase collocations, the discourse structure and cultural symbol.

First, teachers should advise students to read extensively. Extensive reading is more suitable for the analysis of model essays with striking structure, logic and prominent writing features. In model essays, the authors express their views clearly with the language of strong logic and coherence between sentences. Through the understanding and appreciation of model essays, students can have a holistic understanding of the characteristics of English writing, so that they can fully grasp the appropriate methods to practice English writing and make their own writing more authentic. In addition to make students generally understand the essays, teachers can also analyze key sentence patterns to help students deepen the understanding of these important sentence structures. Only when they read more English with typical and authentic sentence structures, can they have a better grasp of English grammar.

Besides extensive reading, college students should also realize the importance of recitation in English writing. In fact, although recitation is time-consuming and effort-taking, it really helps. By reciting good examples, students can grasp the collocation meanings of certain words more firmly, so that they can make no mistakes in their English writing. Moreover, recitation of the well-known aphorisms can add a lot to their compositions. Starting from the initial imitation, student can first learn to polish their language in their compositions, and then gradually master the skill of creative use of language memes to make innovations in the writing, finally further improving the writing skills

Finally, teachers can organize students to practice English writing through topic expansion. Teachers can give students certain situations to complete English writing independently, so that teachers can fully understand in what aspects students are stronger when practicing writing, and in what aspects they still need further improvement. According to the advantages and disadvantages of students, teachers can tailor different learning plans for different students, so as to truly carry out the teaching of English writing with clear target, and thus better ensure the efficiency of the teaching of writing.

\section{CONCLUSION}

English writing, as one of the most important and difficult part in English teaching, has always troubled college English teachers and college students. The introduction of language memes into English writing teaching will inevitably help the majority of English teachers to gain inspiration and help them improve the efficiency of their teaching.

From the perspective of memes, imitation and innovation can coexist harmoniously. In language learning, we imitate for the purpose to achieve innovation. Therefore, imitation should be regarded as the necessary means and process of innovation, and innovation as the purpose and result of imitation. Teachers can give full play to the important role of model texts in the teaching of writing and promote students to make progress in English vocabulary learning, grammatical knowledge and cultural understanding. This method of teaching is bound to help students gradually get rid of the psychological resistance to English writing and achieve continuous improvement in this aspect. In the process of practicing English writing, teacher should advocate imitation, let students make constant progress in imitation, improve in imitation and create in imitation.

\section{REFERENCES}

[1] Blackmore, S. The Meme Machine [M].Oxford: OUP, 1999. Dawkins, R. The Selfish Gene [M] .New York: Oxford University Press, 1976.

[2] He Ziran, He Xuelin, Memetics and Social Pragmatics [J]. Modern Foreign Languages, 2003 (2): 201-204.

[3] Zhang Lixia Teaching of College English Writing from the Perspective of Memetics [J]. Journal of XingTai University, 2010 (12): 49-51.

[4] Cai Shaolian, Memetics and Language Variation [J]. Journal of Guangdong University of Foreign Studies, 2006 (8): 63-67.

[5] Han Zhengzheng, Application of Memetics in Senior English Vocabulary Teaching [D]. Master's Dissertation, Shandong Normal University, 2014 (6): 16.

[6] He Ziran. Memes in Languages [J] .Science of Languages, 2005(6).

[7] Xie Chaoqun, He Ziran. On Language Memes [J] .Modern English. 